\title{
CAMA
}

Centre for Applied Macroeconomic Analysis

\section{Optimal Macroprudential Policy}

\section{CAMA Working Paper 51/2013 August 2013}

\section{Ko Munakata}

Bank of Japan

Koji Nakamura

Bank of Japan

Yuki Teranishi

Department of Business and Commerce, Keio University, and

Centre for Applied Macroeconomic Analysis (CAMA), ANU

\section{Abstract}

We introduce financial market friction through search and matching in the loan market into a standard New Keynesian model. We reveal that the second order approximation of social welfare includes the terms related to credit, such as credit market tightness, the volume of credit, and the loan separation rate, in addition to the inflation rate and consumption under financial market friction. Our analytical result justifies why optimal policy should take credit variation into account. We introduce monetary policy and macroprudential policy measures for financial stability into the model. The optimal outcome is achieved through monetary and macroprudential policies by taking into account not only price stability but also financial stability. 


\section{Keywords}

Optimal macroprudential policy; optimal monetary policy; financial market friction

\section{JEL Classification}

E44; E52; E61

\section{Address for correspondence:}

(E) cama.admin@anu.edu.au

The Centre for Applied Macroeconomic Analysis in the Crawford School of Public Policy has been established to build strong links between professional macroeconomists. It provides a forum for quality macroeconomic research and discussion of policy issues between academia, government and the private sector.

The Crawford School of Public Policy is the Australian National University's public policy school, serving and influencing Australia, Asia and the Pacific through advanced policy research, graduate and executive education, and policy impact. 


\title{
Optimal Macroprudential Policy*
}

\author{
Ko Munakata ${ }^{\dagger} \quad$ Koji Nakamura ${ }^{\ddagger}$ \\ Bank of Japan \\ Yuki Teranishi ${ }^{\S}$ \\ Department of Business and Commerce, Keio University and \\ Centre for Applied Macroeconomic Analysis (CAMA), ANU
}

August 2013

\begin{abstract}
We introduce financial market friction through search and matching in the loan market into a standard New Keynesian model. We reveal that the second order approximation of social welfare includes the terms related to credit, such as credit market tightness, the volume of credit, and the loan separation rate, in addition to the inflation rate and consumption under financial market friction. Our analytical result justifies why optimal policy should take credit variation into account. We introduce monetary policy and macroprudential policy measures for financial stability into the model. The optimal outcome is achieved through monetary and macroprudential policies by taking into account not only price stability but also financial stability.
\end{abstract}

JEL Classification: E44; E52; E61

Keywords: $\quad$ Optimal macroprudential policy; optimal monetary policy; financial market friction

\footnotetext{
${ }^{*}$ We thank Kosuke Aoki for valuable suggestions and comments, and seminar participants at Hitotsubashi University and Summer Workshop on Economic Theory 2013. Views expressed in this paper are those of the authors and do not necessarily reflect the official views of the Bank of Japan.

${ }^{\dagger}$ E-mail: kou.munakata@boj.or.jp

${ }^{\ddagger}$ E-mail: kouji.nakamura@boj.or.jp

${ }^{\S}$ E-mail: yukitera@fbc.keio.ac.jp
} 


\section{Introduction}

Financial crises reveal critical roles of financial markets by inducing real economic disruptions. Under such a situation, accompanied with a lack of room for monetary policy, policy makers shed light on policy measures including macroprudential policy for financial stability as a new tool of macro economic policy.

Some empirical and theoretical studies clarify the need of policy measures for financial stability. Borio (2011) empirically shows a difference between financial cycles and business cycles and then justifies the necessity of coexistence with monetary policy and macroprudential policy. ${ }^{1}$ Quantitative studies for optimal policy under well-known models with financial friction have started to be conducted. For example, Quint and Rabanal (2011) assume the DSGE model with real, nominal and financial frictions, and study the optimal combination of monetary and macroprudential policies. They show that social welfare improves when the policy maker's objective function includes the credit term, implying that macroprudential policies are quantitatively important. Similar approach is taken by Suh (2012) and Kannan, Rabanal, and Scott (2012) with some difference in DSGE models. Suh (2012) shows that macroprudential policy should respond to credit to improve social welfare apart from monetary policy responses to the output gap and the inflation rate. Kannan, Rabanal, and Scott (2012) show that monetary policy reaction to credit growth can help macroeconomic stabilization. These positive analyses, however, do not provide the answer for why counting credit in policy can improve welfare.

In this paper, we aim to reveal a criteria for optimal policy under financial market friction. Our focus is on a normative analysis rather than a positive analysis. To introduce financial friction into a standard New Keynesian model, we assume search and matching in the loan market, following Wasmer and Weil (2000) and Den Haan, Ramey, and Watson (2003). ${ }^{234}$ Based on the model, we approximate the consumer's welfare function in the sec-

\footnotetext{
${ }^{1}$ Drehmann, Borio, and Tsatsaronis (2012) also show such empirical results.

${ }^{2}$ Blanchflower and Oswald (1998) and Peterson and Rajan (2002) empirically show that search and matching frictions play an important role in the loan market.

${ }^{3}$ This type of search and matching friction is also assumed in the labor market as in Mortensen and Pissarides (1994) and Rogerson, Shimer, and Wright (2005). Ravenna and Walsh (2011) derive the quadratic welfare function in the model with search and matching friction in the labor market.

${ }^{4}$ Different types of financial frictions are assumed in other former studies. Bernanke, Gertler, and Gilchrist (1999, henceforth BGG), which is the first to stress that credit market imperfections have a signif-
} 
ond order and reveal the importance of optimal policy for financial stability. A new finding is that an approximated welfare function includes a term closely related to the volume of credit in addition to the inflation rate and consumption. This result theoretically justifies the necessity of financial stability for optimal policy. Then, we introduce monetary policy and macroprudential policy. Macroprudential policy aims to achieve financial stability. We show that optimal policy outcomes change according to the type of macroprudential policy. When the degree of competition in the loan market through Nash bargaining is endogenized and macroprudential policy, which is interpreted as a type of a financial regulation policy, intervenes in such competition, optimal macroprudential policy perfectly stabilizes the inflation rate to a cost-push shock accompanied with monetary policy. This is because macroprudential policy contributes to price stability through the cost channel. When a macroprudential policy intervenes in endogenous credit separation, this macroprudential policy can be interpreted as a total lending control. In this case, a welfare function additionally includes terms for credit separation and the optimal macroprudential policy adjusts the separation rate by taking into account a trade-off between the separation rate, credit market tightness, the inflation rate, and consumption. In any case, macroprudential policy for financial stability has a close relationship with price stability and consequently with monetary policy.

The rest of the paper is organized as follows. The following section sets up a model. In Section 3, we derive the second order approximation from the consumer's utility function and comment on its properties. In Section 4, we show the linearized system of the model. In Section 5, we derive an optimal monetary policy and show the properties of this optimal monetary policy. In Section 6, we derive optimal macroprudential policy for financial stability under various settings and reveal the interaction between optimal macroprudential policy and optimal monetary policy. In Section 7, we conclude the paper.

icant influence on business cycle dynamics. In the BGG model, this financial market wedge is determined by time-varying leverage, in that endogenous mechanisms in credit markets work to amplify and propagate shocks to the economy. In Bianchi (2010), financial market friction is introduced by externalities in which private agents undervalue the dynamics of net worth since the agents fail to internalize the spillover effect between them. 


\section{The Model}

\subsection{Household}

A representative household in our model enters the goods market to consume $C_{t}$ in real terms with price $P_{t}$, and receives $\Pi_{t}$ as a lump-sum profit from wholesale firms and a bank in real terms. In addition, the household deposits $D_{t}$ in a bank account at the beginning of time $t$, and receives the deposit back with a nominal interest rate $R_{t}^{D}$ at the end of time $t$.

Assuming that the utility of the household depends only on consumption $C_{t}$, the household's problem is expressed as

$$
\max _{C, D} \mathrm{E}_{t} \sum_{i=0}^{\infty} \beta^{i} u\left(C_{t+i}\right),
$$

subject to budget constraint

$$
C_{t}=\Pi_{t}+\frac{R_{t-1}^{D} D_{t-1}-D_{t}}{P_{t}} .
$$

We can assume the following utility function.

$$
u\left(C_{t}\right) \equiv \frac{C_{t}^{1-\sigma}}{1-\sigma},
$$

where $\sigma$ is a coefficient of relative risk aversion of the household.

This optimization problem leads to

$$
\begin{gathered}
\lambda_{t}=C_{t}^{-\sigma}, \\
1=\beta \mathrm{E}_{t} \frac{\lambda_{t+1}}{\lambda_{t}} \frac{P_{t}}{P_{t+1}} R_{t}^{D},
\end{gathered}
$$

where $\lambda_{t}$ is the Lagrangian multiplier in the household's optimization problem.

It is assumed that the consumption $C_{t}$ consists of goods labeled by $j \in[0,1]$. The consumption of each good $c_{t}(j)$ is related to the total consumption $C_{t}$ by

$$
C_{t}=\left[\int_{0}^{1} c_{t}(j)^{\frac{\varepsilon_{t}-1}{\varepsilon_{t}}} d j\right]^{\frac{\varepsilon_{t}}{\varepsilon_{t}-1}},
$$

where $\varepsilon_{t} \in(1, \infty)$ is an exogenous stochastic variable related to the elasticity of substitution. The household chooses the level of consumption of each good $c_{t}(j)$ in order to 
minimize the cost $\int_{0}^{1} p_{t}(j) c_{t}(j) d j$, given the level of total consumption $C_{t}$ and the price of each good $p_{t}(j)$. This minimization yields

$$
c_{t}(j)=\left[\frac{p_{t}(j)}{P_{t}}\right]^{-\varepsilon_{t}} C_{t}
$$

where

$$
P_{t} \equiv\left[\int_{0}^{1} p_{t}(j)^{1-\varepsilon_{t}} d j\right]^{\frac{1}{1-\varepsilon_{t}}} .
$$

\subsection{Wholesale Firms}

Each firm wanting a credit line in the credit market at time $t$ is a credit seeker. The number of credit seekers is $u_{t}$, the total number of credit lines is $L_{t}$, and the amount of each credit line in real terms is $a$. If a firm has a credit contract at time $t-1$ but fails to receive an update on the credit line with the probability $\rho$ at time $t$, the firm becomes a credit seeker. On the other hand, if a firm does not have a credit contract at time $t-1$, it automatically becomes a credit seeker at time $t$. Under this setting, the number of credit seekers at time $t$ is obtained by

$$
u_{t}=1-(1-\rho) L_{t-1}
$$

Credit seeking firms participate in the bargaining of credit lines with a representative bank. As a result of the matching process, $L_{t}$ (the number of credit lines at time $t$ ) is related to $L_{t-1}$ by

$$
L_{t}=(1-\rho) L_{t-1}+p_{t}^{F} u_{t}
$$

where $p_{t}^{F}$ is the probability of getting a credit line for each credit seeking firm.

When a firm has a credit line, the firm uses the amount of credit $a$ to buy retail goods $a(j)$, which are then used as an input or a sweat cost to produce wholesale goods with productivity $Z$. A firm's gain when it has a credit line is then

$$
f_{t}^{1}=\frac{Z}{\mu_{t}}-a R_{t}^{L}+\beta \mathrm{E}_{t} \frac{\lambda_{t+1}}{\lambda_{t}}\left\{(1-\rho) f_{t+1}^{1}+\rho\left[p_{t+1}^{F} f_{t+1}^{1}+\left(1-p_{t+1}^{F}\right) f_{t+1}^{0}\right]\right\},
$$

where $R_{t}^{L}-1$ is the real interest rate for the credit, $\mu_{t} \equiv \frac{P_{t}}{P_{t}^{w}}$ is the price markup by retail firms, and $P_{t}^{w}$ is the price of a wholesale good. The first two terms show the net profit 
from production at time $t$ and the third term is the discounted present value of the future profit. On the other hand, a firm's gain when it fails to receive a credit line is

$$
f_{t}^{0}=\beta \mathrm{E}_{t} \frac{\lambda_{t+1}}{\lambda_{t}}\left[p_{t+1}^{F} f_{t+1}^{1}+\left(1-p_{t+1}^{F}\right) f_{t+1}^{0}\right] .
$$

Since the firm cannot obtain a credit line, it does not produce at time $t$ and it only has the discounted future values. These equations imply that the gain from a credit line for a credit seeking firm is

$$
f_{t} \equiv f_{t}^{1}-f_{t}^{0}=\frac{Z}{\mu_{t}}-a R_{t}^{L}+\beta \mathrm{E}_{t} \frac{\lambda_{t+1}}{\lambda_{t}}(1-\rho)\left(1-p_{t+1}^{F}\right) f_{t+1}
$$

\subsection{Bank}

A representative bank decides on the number of credit vacancies $v_{t}$ to post in order to maximize its profit $B_{t}$ with respect to $L_{t}$

$$
B_{t}=\left(R_{t}^{L}-1\right) a L_{t}-\frac{\left(R_{t}^{D}-1\right) D_{t}}{P_{t}}-\kappa v_{t}+\beta \mathrm{E}_{t} \frac{\lambda_{t+1}}{\lambda_{t}} B_{t+1},
$$

subject to

$$
L_{t}=(1-\rho) L_{t-1}+q_{t}^{B} v_{t},
$$

where $\kappa$ is a cost for posting each credit vacancy and $q_{t}^{B}$ is the vacancy filling rate. In reality, $\kappa$ includes the cost of collecting borrowers' information and examining the loan applications. This maximization problem yields

$$
\frac{\kappa}{q_{t}^{B}}=\left(R_{t}^{L}-1\right) a+\beta \mathrm{E}_{t} \frac{\lambda_{t+1}}{\lambda_{t}}(1-\rho) \frac{\kappa}{q_{t+1}^{B}} .
$$

The bank's expected gain from one credit line should be, with free entry, the same as the cost of a vacancy post. This condition implies that the bank's gain for a credit line is

$$
J_{t}=\frac{\kappa}{q_{t}^{B}} .
$$

We assume that the cost of posting credit vacancies $\kappa v_{t}$ is again paid for by consumption of retail goods $v_{t}(j)$, in a similar way as the household consumption $C_{t}$ and the firms' input for production $a$. Therefore, the demand for good $j$ and the total demand are given by

$$
y_{t}^{d}(j) \equiv c_{t}(j)+a(j) L_{t}+\kappa v_{t}(j)
$$


and

$$
Y_{t}^{d} \equiv C_{t}+a L_{t}+\kappa v_{t},
$$

respectively, where

$$
y_{t}^{d}(j)=\left[\frac{P_{t}(j)}{P_{t}}\right]^{-\varepsilon_{t}} Y_{t}^{d}
$$

\subsection{Retail Firms}

A retail firm producing goods $j$ faces the demand given by the equation (8), and it has to pay $P_{t}^{w}$ to buy wholesale goods as an input to produce the final goods. In order to introduce the price stickiness, it is assumed that a firm can adjust its price each period with probability $1-\omega$ as in the model by Calvo (1983). The profit maximization problem of a retail firm when it has a chance to adjust its price $P_{t}^{*}$ becomes

$$
\max _{P_{t}^{*}} \sum_{i=0}^{\infty}(\omega \beta)^{i} \mathrm{E}_{t}\left[\left(\frac{\lambda_{t+i}}{\lambda_{t}}\right)\left(\frac{(1+\tau) P_{t}^{*}-P_{t+i}^{w}}{P_{t+i}}\right)\left(\frac{P_{t}^{*}}{P_{t+i}}\right)^{-\varepsilon_{t+i}} Y_{t+i}^{d}\right],
$$

where the demand equation (8) is used. We here assume that the subsidy for firms $\tau$ is set to ensure that the price flexibility is achieved at the efficient steady-state equilibrium discussed below. Note that the average price level $P_{t}$ is given by

$$
P_{t}^{1-\varepsilon_{t}}=(1-\omega)\left(P_{t}^{*}\right)^{1-\varepsilon_{t}}+\omega P_{t-1}^{1-\varepsilon_{t}} .
$$

\subsection{Loan Market Matching}

The number of new credit matches is

$$
p_{t}^{F} u_{t}=q_{t}^{B} v_{t}=\chi u_{t}^{1-\alpha} v_{t}^{\alpha}
$$

in a Cob-Douglas form where $\alpha(0<\alpha<1)$ is a substitution for $u_{t}$ and $v_{t}$, and $\chi$ is a constant parameter for matching. To make the calculation clearer, we use the credit market tightness equation

$$
\theta_{t}=\frac{v_{t}}{u_{t}},
$$

so that 


$$
\begin{gathered}
v_{t}=\theta_{t} u_{t}, \\
p_{t}^{F}=\chi \theta_{t}^{\alpha}, \\
q_{t}^{B}=\chi \theta_{t}^{\alpha-1}, \\
L_{t}=(1-\rho) L_{t-1}+\chi \theta_{t}^{\alpha} u_{t} .
\end{gathered}
$$

In the loan market, the total gain from loan extension is the sum of credit seeking firms' gain $f_{t}$ and the bank's gain $J_{t}$ as follows

$$
\max _{R^{L}} f_{t}^{b} J_{t}^{1-b}
$$

where $b$ is the bargaining power of credit seeking firms. This is an asymmetric Nash bargaining condition. By taking the first order condition with respect to $R_{t}^{L}$,

$$
(1-b) f_{t}=b J_{t}
$$

For convenience, we simplify equations (5) and (6) by using equations (10), (11), (13), and (7) to eliminate $p_{t}^{F}, q_{t}^{B}, f_{t}$, and $J_{t}$, yielding

$$
\frac{b}{1-b} \frac{\kappa}{\chi} \theta_{t}^{1-\alpha}=\frac{Z}{\mu_{t}}-a R_{t}^{L}+\beta \mathrm{E}_{t} \frac{\lambda_{t+1}}{\lambda_{t}}(1-\rho)\left(1-\chi \theta_{t+1}^{\alpha}\right) \frac{b}{1-b} \frac{\kappa}{\chi} \theta_{t+1}^{1-\alpha}
$$

and

$$
\frac{\kappa}{\chi} \theta_{t}^{1-\alpha}=\left(R_{t}^{L}-1\right) a+\beta \mathrm{E}_{t} \frac{\lambda_{t+1}}{\lambda_{t}}(1-\rho) \frac{\kappa}{\chi} \theta_{t+1}^{1-\alpha},
$$

respectively. If we further eliminate $R_{t}^{L}$ from these equations, we obtain the following condition that relates to the markup $\mu_{t}$ for credit market tightness $\theta_{t}$ :

$$
\begin{aligned}
\frac{Z}{\mu_{t}} & =a+\frac{1}{1-b} \frac{\kappa}{\chi} \theta_{t}^{1-\alpha} \\
& -\beta \mathrm{E}_{t} \frac{\lambda_{t+1}}{\lambda_{t}}(1-\rho) \frac{1}{1-b}\left(\frac{\kappa}{\chi} \theta_{t+1}^{1-\alpha}-b \kappa \theta_{t+1}\right) .
\end{aligned}
$$




\subsection{Market Clearing Condition}

Since one unit of wholesale goods is needed as an input to produce one unit of each retail good $j$, the market clearing condition for wholesale goods is

$$
Z L_{t}=\int_{0}^{1} y_{t}^{d}(j) d j
$$

Together with the demand equation for retail goods (8), the following market clearing condition is obtained:

$$
\frac{Z L_{t}}{Q_{t}}=C_{t}+a L_{t}+\kappa v_{t}
$$

where

$$
Q_{t} \equiv \int_{0}^{1}\left[\frac{P_{t}(j)}{P_{t}}\right]^{-\varepsilon_{t}} d j
$$

represents the dispersion of prices of retail goods due to price stickiness for retail firms.

\section{$3 \quad$ Welfare Criteria}

\subsection{Efficient Steady-State Equilibrium}

The second order expansion of household's utility function is set around efficient steadystate equilibrium, which is the equilibrium designed by a social planner without credit matching inefficiency or price dispersion. Such a situation can only be achieved (1) when the Hosios condition $b=1-\alpha$ for the bargaining power of firm $b$ and matching share $\alpha$ is satisfied and (2) when the subsidy for retail firms $\tau$ is chosen to make sure $\bar{\mu}=\frac{\varepsilon}{(\varepsilon-1)(1+\tau)}=$ 1. Under these assumptions, the optimization problem for the social planner is expressed as

$$
\begin{aligned}
& \max _{C, L, u, \theta} \mathrm{E}_{t} \sum_{i=0}^{\infty} \beta^{i}\left\{\frac{C_{t+i}^{1-\sigma}}{1-\sigma}+\lambda_{t+i}\left[Z L_{t+i}-a L_{t+i}-\kappa \theta_{t+i} u_{t+i}-C_{t+i}\right]\right. \\
& \left.+\psi_{t+i}\left[(1-\rho) L_{t+i-1}+\chi \theta_{t+i}^{\alpha} u_{t+i}-L_{t+i}\right]+s_{t+i}\left[u_{t+i}-1+(1-\rho) L_{t+i-1}\right]\right\},
\end{aligned}
$$

where $\lambda_{t}, \psi_{t}$, and $s_{t}$ are Lagrangian multipliers for the constraints.

The solution to this optimization problem yields the condition: 


$$
Z-a-\frac{\kappa \bar{v}}{\alpha \rho \bar{L}}=-\beta(1-\rho) \frac{\kappa \bar{v}}{\alpha \rho \bar{L}}\left(1-(1-\alpha) \frac{\rho \bar{L}}{\bar{u}}\right),
$$

for the efficient steady-state equilibrium. This equation is simplified for convenience as

$$
\delta_{1}=-\beta \delta_{2}
$$

Note that the bar above each variable (e.g., $\bar{v}$ ) implies the efficient steady-state value of the variable $\left(v_{t}\right)$.

\subsection{Policy Objective Function}

The second order expansion of a household's utility function around the efficient steady state yields

$$
u\left(C_{t}\right) \simeq u(\bar{C})+u_{c} \bar{C}\left(\widehat{c}_{t}+\frac{1}{2} \widehat{c}_{t}^{2}\right)-\frac{1}{2} \sigma u_{c} \bar{C} \widehat{c}_{t}^{2},
$$

where $\widehat{c}_{t}$ is the log-deviation of $C_{t}$ from the efficient steady-state value $\bar{C}$. The goal of the following calculation in this subsection is to express this utility $u\left(C_{t}\right)$ by only $\widehat{l}_{t}, \widehat{l}_{t-1}$, and the inflation rate $\pi_{t} \equiv \widehat{p}_{t}-\widehat{p}_{t-1}$. This calculation closely follows the derivation of a policy objective function by Ravenna and Walsh (2011) for search and matching in the labor market. By using the market clearing condition of the equation (15), we can see

$$
\widehat{c}_{t}+\frac{1}{2} \widehat{c}_{t}^{2}=-\frac{Z \bar{L}}{\bar{C}} \widehat{q}_{t}+\frac{(Z-a) \bar{L}}{\bar{C}}\left(\widehat{l}_{t}+\frac{1}{2} \widehat{l}_{t}^{2}\right)-\frac{\kappa \bar{v}}{\bar{C}}\left(\widehat{v}_{t}+\frac{1}{2} \widehat{v}_{t}^{2}\right) .
$$

Note that the efficient steady-state value of the price dispersion term $Q_{t}$ is $\bar{Q}=1$, and the $\log$-deviation of this term $\widehat{q}_{t}$ is already in the second order, as is shown below.

Using equation (9)

$$
\widehat{v}_{t}=\widehat{u}_{t}+\widehat{\theta}_{t}
$$

and equation (4)

$$
\widehat{u}_{t}+\frac{1}{2} \widehat{u}_{t}^{2}=-\eta\left(\widehat{l}_{t-1}+\frac{1}{2} \widehat{l}_{t-1}^{2}\right)
$$

where

$$
\eta \equiv(1-\rho) \frac{\bar{L}}{\bar{u}} .
$$

Then, we obtain up to the second order

$$
\widehat{v}_{t}+\frac{1}{2} \widehat{v}_{t}^{2}=\left(\widehat{\theta}_{t}+\frac{1}{2} \widehat{\theta}_{t}^{2}\right)-\eta\left(\widehat{l}_{t-1}+\frac{1}{2} \widehat{l}_{t-1}^{2}\right)-\eta \widehat{\theta}_{t} \widehat{l}_{t-1} .
$$


By using this equation and equation (12), we can eliminate $\widehat{\theta}_{t}$ and get

$$
\begin{aligned}
u\left(C_{t}\right) & =u(\bar{C})-u_{c} Z \bar{L} \widehat{l}_{t} \\
& +u_{c} \bar{C}\left[\frac{\bar{L}}{\bar{C}}\left(\delta_{1} \widehat{l}_{t}+\delta_{2} \widehat{l}_{t-1}\right)+\frac{\bar{L}}{2 \bar{C}}\left(\delta_{1} \widehat{l}_{t}^{2}+\delta_{2} \widehat{l}_{t-1}^{2}\right)-\frac{\kappa \bar{v}}{\bar{C}} \frac{1-\alpha}{2(\alpha \rho)^{2}}\left(\widehat{l}_{t}-\rho_{u} \widehat{l}_{t-1}\right)^{2}\right] \\
& -\frac{1}{2} \sigma u_{c} \bar{C}\left(\frac{\bar{L}}{\bar{C}}\right)^{2}\left(\delta_{1} \widehat{l}_{t}+\delta_{2} \widehat{l}_{t-1}\right)^{2},
\end{aligned}
$$

where

$$
\rho_{u} \equiv 1-\rho-\rho \eta
$$

Thus, the utility of equation (1) is rewritten as

$$
\begin{aligned}
\sum_{i=0}^{\infty} \beta^{i} u\left(C_{t+i}\right) & =\frac{u(\bar{C})}{1-\beta}-u_{c} Z \bar{L} \sum_{i=0}^{\infty} \beta^{i} \widehat{q}_{t+i} \\
& +u_{c} \bar{L} \sum_{i=0}^{\infty} \beta^{i}\left(\delta_{1} \widehat{l}_{t+i}+\delta_{2} \widehat{l}_{t+i-1}\right) \\
& +\frac{1}{2} u_{c} \bar{L} \sum_{i=0}^{\infty} \beta^{i}\left(\delta_{1} \widehat{l}_{t+i}^{2}+\delta_{2} \widehat{l}_{t+i-1}^{2}\right) \\
& -u_{c} \kappa \bar{v} \frac{1-\alpha}{2(\alpha \rho)^{2}} \sum_{i=0}^{\infty} \beta^{i}\left(\widehat{l}_{t+i}-\rho_{u} \widehat{l}_{t+i-1}\right)^{2} \\
& -\frac{1}{2} \sigma u_{c} \bar{C}\left(\frac{\bar{L}}{\bar{C}}\right)^{2} \sum_{i=0}^{\infty} \beta^{i}\left(\delta_{1} \widehat{l}_{t+i}+\delta_{2} \widehat{l}_{t+i-1}\right)^{2} .
\end{aligned}
$$

By using the efficient steady-state condition given by equation (17), the two terms on the right-hand side of the equation above are shown to depend only on $\widehat{l}_{t-1}$, and the utility becomes

$$
\begin{aligned}
\sum_{i=0}^{\infty} \beta^{i} u\left(C_{t+i}\right) & =-u_{c} Z \bar{L} \sum_{i=0}^{\infty} \beta^{i} \widehat{q}_{t+i} \\
& -u_{c} \kappa \bar{v} \frac{1-\alpha}{2(\alpha \rho)^{2}} \sum_{i=0}^{\infty} \beta^{i}\left(\widehat{l}_{t+i}-\rho_{u} \widehat{l}_{t+i-1}\right)^{2} \\
& -\frac{1}{2} \sigma u_{c} \bar{C}\left(\frac{\bar{L}}{\bar{C}} \delta_{2}\right)^{2} \sum_{i=0}^{\infty} \beta^{i}\left(-\beta \widehat{l}_{t+i}+\widehat{l}_{t+i-1}\right)^{2} \\
& + \text { t.i.p. }
\end{aligned}
$$

where t.i.p. denotes "terms independent of policy." 
Next, we consider the sum over the price dispersion terms $\widehat{q}_{t+i}$. By definition of equation $(16)$,

$$
\begin{aligned}
\widehat{q}_{t} & =\int_{0}^{1} d j \exp \left[-\varepsilon_{t}\left(\widehat{p}_{t}(j)-\widehat{p}_{t}\right)\right]-1 \\
& \simeq-\varepsilon\left(\Delta_{t}^{E}-\widehat{p}_{t}\right)\left(1+\widehat{\varepsilon}_{t}\right)+\frac{1}{2} \varepsilon^{2}\left[\Delta_{t}^{V}+\left(\Delta_{t}^{E}-\widehat{p}_{t}\right)^{2}\right],
\end{aligned}
$$

where $\Delta_{t}^{E} \equiv E_{j} \widehat{p}_{t}(j)=\int_{0}^{1} \widehat{p}_{t}(j) d j$ and $\Delta_{t}^{V} \equiv \operatorname{Var}_{j} \widehat{p}_{t}(j)=E_{j} \widehat{p}_{t}(j)^{2}-\left(E_{j} \widehat{p}_{t}(j)\right)^{2}$. Since the definition of the aggregate price $P_{t}$ given by equation $(3)$ can be used to show that

$$
\Delta_{t}^{E}-\widehat{p}_{t} \simeq-\frac{1}{2}(1-\varepsilon) \Delta_{t}^{V}
$$

Up to the second order in $\widehat{p}_{t}$, we can thus rewrite $\widehat{q}_{t}$ as

$$
\widehat{q}_{t} \simeq \frac{1}{2} \varepsilon \Delta_{t}^{V}
$$

leading to

$$
\sum_{i=0}^{\infty} \beta^{i} \widehat{q}_{t+i}=\frac{1}{2} \varepsilon \sum_{i=0}^{\infty} \beta^{i} \Delta_{t+i}^{V} .
$$

On the other hand, the equation to obtain $\Delta_{t}^{V}$ is written as

$$
\begin{aligned}
\Delta_{t}^{V} & =\operatorname{Var}_{j} \widehat{p}_{t}(j) \\
& =E_{j}\left(\widehat{p}_{t}(j)-\Delta_{t-1}^{E}\right)^{2}-\left(\Delta_{t}^{E}-\Delta_{t-1}^{E}\right)^{2}
\end{aligned}
$$

Here, we remember that only the fraction $1-\omega$ of all firms adjust their prices to $P_{t}^{*}$, while other firms do not change their prices $p_{t-1}(j) . \widehat{p}_{t}^{*}$, the log-deviation of $P_{t}^{*}$, can in turn be expressed by $\widehat{p}_{t}$ and $\widehat{p}_{t-1}$. Hence,

$$
\Delta_{t}^{V} \simeq \omega \Delta_{t-1}^{V}+(1-\omega) E_{j}\left(\frac{1}{1-\omega} \widehat{p}_{t}-\frac{\omega}{1-\omega} \widehat{p}_{t-1}-\widehat{p}_{t-1}\right)^{2}-\left(\widehat{p}_{t}-\widehat{p}_{t-1}\right)^{2},
$$

up to the second order again in $\widehat{p}_{t}$. Using the inflation rate $\pi_{t} \equiv \widehat{p}_{t}-\widehat{p}_{t-1}$, we thus have

$$
\Delta_{t}^{V} \simeq \omega \Delta_{t-1}^{V}+\frac{\omega}{1-\omega} \pi_{t}^{2}
$$

The sum of $\Delta_{t}^{V}$ becomes 


$$
\sum_{i=0}^{\infty} \beta^{i} \Delta_{t+i}^{V}=\Delta_{t}^{V}+\omega \beta \sum_{i=0}^{\infty} \beta^{i} \Delta_{t+i}^{V}+\frac{\omega \beta}{1-\omega} \sum_{i=0}^{\infty} \beta^{i} \pi_{t+i}^{2} .
$$

We therefore obtain

$$
\sum_{i=0}^{\infty} \beta^{i} \Delta_{t+i}^{V}=\frac{\omega \beta}{(1-\omega)(1-\omega \beta)} \sum_{i=0}^{\infty} \beta^{i} \pi_{t+i}^{2}+\text { t.i.p. }
$$

Combining this equation with the equations (20) and (21),

$$
\begin{aligned}
\sum_{i=0}^{\infty} \beta^{i} u\left(C_{t+i}\right) & =-\frac{1}{2} u_{c} Z \bar{L} \frac{\varepsilon}{\delta} \sum_{i=0}^{\infty} \beta^{i} \pi_{t+i}^{2} \\
& -u_{c} \kappa \bar{v} \frac{1-\alpha}{2(\alpha \rho)^{2}} \sum_{i=0}^{\infty} \beta^{i}\left(\widehat{l}_{t+i}-\rho_{u} \widehat{l}_{t+i-1}\right)^{2} \\
& -\frac{1}{2} \sigma u_{c} \bar{C}\left(\frac{\bar{L}}{\bar{C}} \delta_{2}\right)^{2} \sum_{i=0}^{\infty} \beta^{i}\left(-\beta \widehat{l}_{t+i}+\widehat{l}_{t+i-1}\right)^{2} \\
& + \text { t.i.p. }
\end{aligned}
$$

where

$$
\delta \equiv \frac{(1-\omega)(1-\omega \beta)}{\omega} .
$$

We also use the approximations up to the second order

$$
\widehat{\theta}_{t+i}^{2}=\frac{1}{(\alpha \rho)^{2}}\left(\widehat{l}_{t+i}-\rho_{u} \widehat{l}_{t+i-1}\right)^{2}=\frac{1}{(\alpha \rho \eta)^{2}}\left(\widehat{u}_{t+i}-\rho_{u} \widehat{u}_{t+i-1}\right)^{2},
$$

and

$$
\widehat{c}_{t+i}^{2}=\left(\frac{\bar{L}}{\bar{C}} \delta_{2}\right)^{2}\left(-\beta \widehat{l}_{t+i}+\widehat{l}_{t+i-1}\right)^{2},
$$

and finally, we have the following second order expansion of a household's utility function

$$
\sum_{i=0}^{\infty} \beta^{i} u\left(C_{t+i}\right)=-\frac{1}{2} \sum_{i=0}^{\infty} \beta^{i}\left(\lambda_{\pi} \pi_{t+i}^{2}+\lambda_{\theta} \widehat{\theta}_{t+i}^{2}+\lambda_{c} \widehat{c}_{t+i}^{2}\right)+t . i . p .,
$$

where $\lambda_{\pi} \equiv u_{c} Z \bar{L} \frac{\varepsilon}{\delta}, \lambda_{\theta} \equiv u_{c} \kappa \bar{v}(1-\alpha)$ and $\lambda_{c} \equiv \sigma u_{c} \bar{C}$.

We note that, even if we introduce the exogenous productivity shock $Z_{t}$ in the model, we can derive a mathematically-similar formula for the utility by taking the difference from the efficient stochastic state. This point is discussed in the appendix. 
Optimal policy faces a trade-off between the inflation rate, consumption, and credit market tightness. Credit market tightness is a new feature for the optimal policy under loan market friction. Moreover, the approximated welfare function can be transformed as

$$
\sum_{i=0}^{\infty} \beta^{i} u\left(C_{t+i}\right)=-\sum_{i=0}^{\infty} \beta^{i} \frac{1}{2}\left[\lambda_{\pi} \pi_{t+i}^{2}+\frac{\lambda_{\theta}}{(\alpha \rho)^{2}}\left(\widehat{l}_{t+i}-\rho_{u} \widehat{l}_{t+i-1}\right)^{2}+\lambda_{c} \widehat{c}_{t+i}^{2}\right] .
$$

Thus, the optimal policy should respond to changes in credit. This result theoretically supports the papers of Quint and Rabanal (2011), Suh (2012), and Kannan, Rabanal, and Scott (2012), claiming in numerical simulations that the policy should respond to the changes in credit, in addition to the inflation rate and the output gap.

\subsection{Analysis for Welfare Criteria}

In this section, we analyze the dependence of the welfare function on different parameters, especially focusing on the weight of the term corresponding to financial friction.

To start the analysis, we fix the parameter values as shown in Table 1 . We assume that each period corresponds to one quarter, and set the discount factor $\beta=0.99$ and the probability of price adjustment for retail firms as $1-\omega=0.2$. As for the other parameters, since our objective is not to calibrate the model but to illustrate the important characteristics of financial friction in our model, the set of the parameter values in Table 1 is to be taken as just one example, and it is confirmed that the qualitative conclusion in this section can apply to a wide range of parameter values.

As shown in Figure 1, as the cost for posting each credit vacancy $\kappa$ increases, the relative weight for credit to that for the consumption in the approximated welfare function $\left(\lambda_{\theta} / \lambda_{c}\right.$ of the equation (22)) increases. ${ }^{5}$ This is because the wedge of financial market friction increases when $\kappa$ increases since, as shown in equation (15), it is related to the resource of economy used to match the loan $\kappa \bar{v}$.

The same result holds for $\rho$, the probability of failing to receive an update on the credit line. When $\rho$ increases, $\lambda_{\theta} / \lambda_{c}$ increases as shown in Figure $2 .{ }^{6}$ This is also because the

\footnotetext{
${ }^{5}$ The other parameters adopted in the Figure 1 are given by Table 1 . Note that, when the cost for posting each credit vacancy $\kappa$ changes, the steady-state values of the variables $\bar{v}$ and $\bar{C}$ shifts to satisfy the efficient steady-state equilibrium condition as shown in the equation (17).

${ }^{6}$ The other parameters adopted in the Figure 2 are given by Table 1 . Note that the variation of $\rho$ also affects the steady-state values of the variables $\bar{v}$ and $\bar{C}$
} 
increase of $\rho$ raises the cost of holding credit.

These results imply that the relative weight for the credit term increases when the degree of inefficiency to hold credit increases. In other words, as the degree of market imperfection increases, optimal monetary policy should take the credit market condition into account more seriously.

\section{Linearization}

We show the closed linearized system of the economy around efficient equilibrium. For general stochastic non-efficient state, the Calvo-type stickiness introduced in the retail sector leads to the standard Phillips curve with a cost-push shock $\widehat{\varepsilon}_{t}$ as

$$
\pi_{t}=\beta \mathrm{E}_{t} \pi_{t+1}-\delta\left(\frac{1}{\epsilon-1} \widehat{\varepsilon}_{t}+\widehat{\mu}_{t}\right) .
$$

The retail price markup term $\widehat{\mu}_{t}$ in this equation can be obtained by the linearized equation $(14)$,

$$
\begin{aligned}
Z \widehat{\mu}_{t} & =-(1-\alpha) \frac{\kappa \bar{v}}{\alpha \rho \bar{L}}\left(\widehat{\theta}_{t}-\beta \rho_{u} \mathrm{E}_{t} \widehat{\theta}_{t+1}\right) \\
& -\beta \delta_{2} \sigma\left(\mathrm{E}_{t} \widehat{c}_{t+1}-\widehat{c}_{t}\right) .
\end{aligned}
$$

The IS relation is given by

$$
\widehat{c}_{t}=\mathrm{E}_{t} \widehat{c}_{t+1}-\frac{1}{\sigma}\left(\widehat{r}_{t}^{D}-\mathrm{E}_{t} \pi_{t+1}\right),
$$

where we call $\widehat{c}_{t}$ as the output gap.

Credit market tightness is given by

$$
\widehat{\theta}_{t}=\frac{\left(\widehat{l}_{t}-\rho_{u} \widehat{l}_{t-1}\right)}{\alpha \rho} .
$$

The relationship between consumption and credit is given by

$$
\widehat{c}_{t}=\frac{\bar{L} \delta_{2}}{\bar{C}}\left(-\beta \widehat{l_{t}}+\widehat{l}_{t-1}\right)
$$


It is also noteworthy that the log-linearized deviation of the loan interest rate $\widehat{r}_{t}^{L}$ is related to credit market tightness $\widehat{\theta}_{t}$ and the deposit interest rate $\widehat{r}_{t}^{D}$ by the following equation:

$$
\begin{aligned}
a \bar{R}^{L} \widehat{r}_{t}^{L} & =(1-\alpha) \frac{\kappa}{\chi} \bar{\theta}^{1-\alpha} \widehat{\theta}_{t} \\
& -(1-\rho) \beta(1-\alpha) \frac{\kappa}{\chi} \bar{\theta}^{1-\alpha} \mathrm{E}_{t} \widehat{\theta}_{t+1} \\
& +(1-\rho) \beta \frac{\kappa}{\chi} \bar{\theta}^{1-\alpha}\left(\widehat{r}_{t}^{D}-\mathrm{E}_{t} \pi_{t+1}\right)
\end{aligned}
$$

Credit market tightness and the real deposit rate determine the loan interest rate. This equation can be transformed as

$$
\begin{aligned}
a \bar{R}^{L} \widehat{r}_{t}^{L} & =-\beta(1-\rho) \frac{\kappa \bar{\theta}^{1-\alpha}}{\chi}\left[\frac{(1-\alpha)}{\alpha \rho}+\beta \sigma \frac{\bar{L} \delta_{2}}{\bar{C}}\right] \mathrm{E}_{t} \widehat{l}_{t+1} \\
& +\frac{\kappa \bar{\theta}^{1-\alpha}}{\chi}\left[\frac{(1-\alpha)}{\alpha \rho}+\frac{(1-\rho) \beta(1-\alpha) \rho_{u}}{\alpha \rho}+\frac{(1-\rho) \beta \sigma \bar{L} \delta_{2}(1+\beta)}{\bar{C}}\right] \widehat{l}_{t} \\
& -\frac{\kappa \bar{\theta}^{1-\alpha}}{\chi}\left[\frac{(1-\alpha) \rho_{u}}{\alpha \rho}+\frac{(1-\rho) \beta \sigma \bar{L} \delta_{2}}{\bar{C}}\right] \widehat{l}_{t-1} .
\end{aligned}
$$

Thus, the loan interest rate and credit have a close relationship. By using equation (28), it is possible to include the loan rate term in the approximated welfare function. This result is consistent with ones in Teranishi (2008) and Cúrdia and Woodford (2009). Teranishi (2008) shows that under the staggered cost channel model an approximated welfare function includes the growth of the loan interest rate. Cúrdia and Woodford (2009) show that an approximated welfare function includes the credit spread term under the model where households face financial market friction.

\section{Optimal Monetary Policy}

We assume that a central bank control the nominal interest rate on deposits to maximize social welfare, following Woodford (2003). The optimal precommitment policy rule for a central bank under the timeless perspective should therefore be obtained by solving the following minimization problem:

$$
\min _{\pi, c, \theta, r^{D}, l} \mathrm{E}_{t} \sum_{i=0}^{\infty} \beta^{i} \frac{1}{2}\left(\lambda_{\pi} \pi_{t+i}^{2}+\lambda_{\theta} \widehat{\theta}_{t+i}^{2}+\lambda_{c} \widehat{c}_{t+i}^{2}\right)
$$


subject to the Phillips curve of equation (23), the markup of equation (24), the IS relation of equation (25), and the expressions for the credit market tightness of equation (26), and the consumption of equation (27).

Then, optimal monetary policy, which is the nominal interest rate, is given by the first order conditions for $\pi_{t}, \widehat{\theta}_{t}, \widehat{c}_{t}, \widehat{l}_{t}$, and $\widehat{r}_{t}^{D}$, respectively as:

$$
\begin{gathered}
\lambda_{\pi} \pi_{t}+\varphi_{1 t}-\varphi_{1 t-1}-\beta^{-1} \sigma^{-1} \varphi_{2 t-1}=0, \\
\lambda_{\theta} \widehat{\theta}_{t}-\delta(1-\alpha) \frac{\kappa \bar{v}}{Z \alpha \rho \bar{L}}\left(\varphi_{1 t}-\rho_{u} \varphi_{1 t-1}\right)+\varphi_{3 t}=0, \\
\lambda_{c} \widehat{c}_{t}-\frac{\delta \delta_{2} \sigma}{Z}\left(\varphi_{1 t-1}-\beta \varphi_{1 t}\right)+\varphi_{2 t}-\beta^{-1} \varphi_{2 t-1}+\varphi_{4 t}=0, \\
-\frac{1}{\alpha \rho} \varphi_{3 t}+\frac{\beta \rho_{u}}{\alpha \rho} \mathrm{E}_{t} \varphi_{3 t+1}+\frac{\bar{L} \delta_{2} \beta}{\bar{C}} \varphi_{4 t}-\frac{\bar{L} \delta_{2} \beta}{\bar{C}} \mathrm{E}_{t} \varphi_{4 t+1}=0, \\
\varphi_{2 t}=0,
\end{gathered}
$$

where $\varphi_{1 t}, \varphi_{2 t}, \varphi_{3 t}$, and $\varphi_{4 t}$ are Lagrangian multipliers for the Phillips curve of equation (23), the IS relation of equation (25), the expressions for credit market tightness of equation (26), and the consumption of equation (27), respectively.

\section{Optimal Macroprudential Policy}

\subsection{Intervention for Nash Bargaining}

We introduce a macroprudential policy that intervenes in the setting of the loan interest rate between a firm and a bank through Nash bargaining. The monetary authority control the parameter $b$ of Nash bargaining as

$$
\max _{R^{L}} f_{t}^{b_{t}} J_{t}^{1-b_{t}},
$$

where $b_{t}$ is the policy variable of the monetary authority. In reality, the monetary authority controls the degree of competition in the loan market by changing the financial regulations on banks' competition. In this case, the retail price markup term $\widehat{\mu}_{t}$ in equation (24) changes to become 


$$
\begin{aligned}
Z \widehat{\mu}_{t} & =-(1-\alpha) \frac{\kappa \bar{v}}{\alpha \rho \bar{L}}\left(\widehat{\theta}_{t}-\beta \rho_{u} \mathrm{E}_{t} \widehat{\theta}_{t+1}\right) \\
& -\beta \delta_{2} \sigma\left(\mathrm{E}_{t} \widehat{c}_{t+1}-\widehat{c}_{t}\right) \\
& -\frac{b}{(1-b)^{2}} \frac{\kappa \bar{v}}{\rho \bar{L}}\left(\widehat{b}_{t}-\beta \rho_{u} \mathrm{E}_{t} \widehat{b}_{t+1}\right) .
\end{aligned}
$$

The welfare function and other parts of the model, however, do not change. Then, the optimal policy measure for financial stability is given by

$$
\varphi_{1 t}-\rho_{u} \varphi_{1 t-1}=0
$$

Accompanied with optimal monetary policy, under optimal macroprudential policy, the inflation rate is fixed to zero, and other variables are also zero against the cost-push shock. This is because financial stability leads to price stability via the cost channel. This case shows that macroprudential policy for financial stability can hold a close relationship with price stability and ultimately with monetary policy.

\subsection{Intervention for Credit Separation}

Another way to intervene in the credit market could be limiting or controlling the credit separation rate $\rho .^{7}$ In this macroprudential policy, the monetary authority controls the total volume of credit. If the change in $\rho$ affects no other exogenous parameters, it can be shown in our model that the utility is maximized by always setting $\rho$ to zero. In the real economy, however, constraining natural separation of credit between banks and firms result in a deterioration of productivity. ${ }^{8}$ To allow policy makers to control the separation rate $\rho_{t}$, we introduce the following relationship between the average productivity of wholesale firms $Z_{t}$ and the separation rate $\rho_{t}$ :

$$
Z_{t}=f\left(\rho_{t}\right)
$$

where $f$ is a monotonically-increasing concave function. We then assume that the expansion of the above relationship up to the second order from a steady-state value can be expressed as

\footnotetext{
${ }^{7}$ We can also make the credit vacancies $\kappa$ or the matching parameter $\chi$ as policy variables.

${ }^{8}$ A similar feature for the separation between workers and firms is endogenously captured by the matching model by Mortensen and Pissarides (1994).
} 


$$
Z\left(\widehat{z}_{t}+\frac{1}{2} \widehat{z}_{t}^{2}\right)=\bar{\rho}\left[f_{1} \widehat{\rho}_{t}+\frac{1}{2}\left(f_{1}+f_{2} \bar{\rho}\right) \widehat{\rho}_{t}^{2}\right],
$$

where the first and the second derivative of function $f$ under the efficient steady-state equilibrium satisfy $f_{1}>0$ and $f_{2} \leq 0$, respectively.

In addition to equation (17), the efficient steady-state condition becomes,

$$
(1-\bar{\rho}) f_{1}=\delta_{2}
$$

where $\bar{\rho}$ can be nonzero. In this case, the welfare function becomes

$$
\begin{aligned}
\sum_{i=0}^{\infty} \beta^{i} u\left(C_{t+i}\right) & =-\frac{1}{2} \sum_{i=0}^{\infty} \beta^{i}\left(\lambda_{\pi} \pi_{t+i}^{2}+\lambda_{\theta} \widehat{\theta}_{t+i}^{2}+\lambda_{c} \widehat{c}_{t+i}^{2}+\lambda_{\rho} \widehat{\rho}_{t+i}^{2}\right) \\
& +\sum_{i=0}^{\infty} \beta^{i} \psi_{\rho} \widehat{\rho}_{t+i}\left(\widehat{l}_{t+i}-\widehat{l}_{t+i-1}\right)+t . i . p .
\end{aligned}
$$

where $\lambda_{\rho} \equiv u_{c} \bar{L} \bar{\rho}^{2}\left|f_{2}\right|$ and $\psi_{\rho} \equiv u_{c} \bar{L} \bar{\rho} f_{1}$. See the appendix for the details of the calculation.

The implication of this equation is clear. The fact that the last term is linear in $\widehat{\rho}$ suggests that, when the amount of credit increases, society is better off by setting the separation rate higher than the efficient equilibrium value and so by reducing credit. The second-order term $\lambda_{\rho} \widehat{\rho}_{t+i}^{2}$ is then the cost incurred by excessive control of $\widehat{\rho}$ from the concavity of function $f$. When the probability of failing to receive an update on the credit line $\rho$ increases, the relative weight for the terms of the separation rate increase. This is because the increase of $\rho$ raises the cost of holding credit.

The time-variation in the separation rate modifies the relationship between credit tightness and the amount of credit as

$$
\widehat{\theta}_{t}=\frac{1}{\alpha \bar{\rho}}\left[\widehat{l}_{t}-\rho_{u} \widehat{l}_{t-1}+\bar{\rho}\left(1-\frac{\bar{\rho} \bar{L}}{\bar{u}}\right) \widehat{\rho}_{t}\right] .
$$

In addition, the markup equation is modified as

$$
\begin{aligned}
Z \widehat{\mu}_{t} & =-(1-\alpha) \frac{\kappa \bar{v}}{\alpha \bar{\rho} \bar{L}}\left(\widehat{\theta}_{t}-\beta \rho_{u} \mathrm{E}_{t} \widehat{\theta}_{t+1}\right) \\
& -\beta \delta_{2} \sigma\left(\mathrm{E}_{t} \widehat{c}_{t+1}-\widehat{c}_{t}\right) \\
& +\delta_{2} \frac{\bar{\rho}}{1-\bar{\rho}}\left(\widehat{\rho}_{t}-\beta \mathrm{E}_{t} \widehat{\rho}_{t+1}\right) .
\end{aligned}
$$


On the other hand, the efficient steady-state condition (35) ensures that the equation (27) between consumption and credit is unchanged under the first order.

The optimal policy is obtained by maximizing the above utility subject to the Phillips curve of equation (23), the modified markup of equation (38), the IS relation of equation (25), and the expressions for the credit market tightness of equation (37), and the consumption of equation (27). This maximization replaces one of the first order conditions (32) by

$$
-\psi_{\rho}\left(\widehat{\rho}_{t}-\beta \mathrm{E}_{t} \widehat{\rho}_{t+1}\right)-\frac{1}{\alpha \rho} \varphi_{3 t}+\frac{\beta \rho_{u}}{\alpha \rho} \mathrm{E}_{t} \varphi_{3 t+1}+\frac{\bar{L} \delta_{2} \beta}{\bar{C}} \varphi_{4 t}-\frac{\bar{L} \delta_{2} \beta}{\bar{C}} \mathrm{E}_{t} \varphi_{4 t+1}=0,
$$

and the first order condition for $\widehat{\rho}_{t}$ is obtained by

$$
\lambda_{\rho} \widehat{\rho}_{t}-\psi_{\rho}\left(\widehat{l}_{t}-\widehat{l}_{t-1}\right)+\frac{\delta}{Z} \delta_{2} \frac{\bar{\rho}}{1-\bar{\rho}}\left(\varphi_{1 t}-\varphi_{1 t-1}\right)-\frac{\rho_{u}}{\alpha(1-\bar{\rho})} \varphi_{3 t}=0,
$$

or by using the equations (29) and (33),

$$
\varphi_{3 t}=\frac{\alpha \bar{\rho}}{\rho_{u}} u_{c} \bar{L}\left[\bar{\rho}(1-\bar{\rho})\left|f_{2}\right| \widehat{\rho}_{t}-\delta_{2}\left(\varepsilon \pi_{t}+\widehat{l}_{t}-\widehat{l}_{t-1}\right)\right] .
$$

The optimal macroprudential policy adjusts the separation rate by taking account of the trade-off between the separation rate, credit market tightness, consumption, and the inflation rate, while all of the separation rate, credit market tightness, and consumption are closely related to the amount of credit $\widehat{l}_{t}$ in equations (27) and (37). In fact, we can explicitly derive the following macroprudential policy by substituting equations (31) and (41) into equation (39) to eliminate $\varphi_{3 t}$ and $\varphi_{4 t}$ :

$$
A_{1} \widehat{\rho}_{t}-\beta A_{2} \mathrm{E}_{t} \widehat{\rho}_{t+1}=A_{3}\left(\varepsilon \pi_{t}+\widehat{l}_{t}-\widehat{l}_{t-1}\right)-\beta \delta_{2} A_{4}\left(\varepsilon \mathrm{E}_{t} \pi_{t+1}+\mathrm{E}_{t} \widehat{l}_{t+1}-\widehat{l}_{t}\right)
$$

where

$$
\begin{aligned}
A_{1} & \equiv \frac{\bar{\rho}}{1-\bar{\rho}} \delta_{2}+\frac{\bar{\rho}(1-\bar{\rho})\left|f_{2}\right|}{\rho_{u}}, \\
A_{2} & \equiv \frac{\bar{\rho}}{1-\bar{\rho}} \delta_{2}+\bar{\rho}(1-\bar{\rho})\left|f_{2}\right|, \\
A_{3} & \equiv \frac{\bar{L} \delta_{2} \beta \sigma}{\bar{C}}+\frac{1}{\rho_{u}}, \\
A_{4} & \equiv \frac{\bar{L} \delta_{2} \beta \sigma}{\bar{C}}+1 .
\end{aligned}
$$


Note that equation (27) is used to eliminate $\widehat{c}_{t}$. The form of equation (42) clearly suggests that the optimal choice of the separation rate is determined by the inflation rate and the increase in credit $\varepsilon \pi_{t}+\widehat{l}_{t}-\widehat{l}_{t-1}$. The monetary authority should pay attention to inflation in addition to credit since the financial market and the real economy are tightly connected. Thus, for both the monetary authority and the central bank, it is essential to internalize another policy each other.

\section{Concluding Remarks}

We introduce search and matching friction into the loan market in a standard New Keynesian model. In this model, the second order approximation of social welfare includes terms relating to credit, such as credit market tightness, the volume of credit, and a loan separation rate, in addition to the inflation rate and the output gap. This is a new finding in the field of optimal policy. The outcome of optimal policy changes in accordance with the type of macroprudential policy for financial stability.

For future research, the following points could be of interest. The model considered in this paper is restricted to the case where the central bank and monetary authority coordinate their policy choices so as to maximize social welfare. An alternative assumption would be that two policy makers set their respective policies in a non-cooperative way. Moreover, we can assume a situation where macroprudential policy can have impact on disturbances, even though monetary policy cannot affect them. Such disturbances can be ones from credit spreads on the policy interest rate. Another issue is a question for what kinds of policies are simple and implementable to replicate the optimal policy measure for financial stability, as is the case with the Taylor rule in optimal monetary policy analysis. In such an analysis, it would be interesting to quantitatively evaluate priority between stabilization of credit, the inflation rate, and the output gap. 


\section{References}

[1] Bernanke, B., Gertler, M., Gilchrist, S., 1996. The Financial Accelerator in a Quantitative Business Cycle Framework. Handbook of Macroeconomics 1, edited by J.B. Taylor and M. Woodford, 1341-1393.

[2] Bianchi, J, 2010. Credit Externalities: Macroeconomic Effects and Policy Implications. American Economic Review: Paper \& Proceedings 100, pp. 398-402.

[3] Blanchflower, D. and A. Oswald. 1998. What Makes an Entrepreneur? Journal of Labor Economics 16-1, pp. 26-60.

[4] Borio, C., 2011. Rediscovering the Macroeconomic Roots of Finanical Stability Policy: Journey Challenges and a Way Forward. BIS Working Papers No. 354.

[5] Calvo, G.A., 1983. Staggered Prices in a Utility-Maximizing Framework. Journal of Monetary Economics 12-3, pp. 983-998.

[6] Cúrdia, V. and M. Woodford, 2009. Credit Friction and Optimal Monetary Policy. Mimeo.

[7] Den Haan, W.J., G. Ramey, and J. Watson, 2003. Liquidity Flows and Fragility of Business Enterprises. Journal of Monetary Economics 50, pp. 1215-1241.

[8] Drehmann, M., C. Borio, and K. Tsatsaronis, 2012. Characterising the Financial Cycle: Don’t Lose Sight of the Medium Term! BIS Working Papers No. 380.

[9] Kannan, P., P. Rabanal, and A. Scott, 2012. Monetary and Macroprudential Policy Rules in a Model with House Price Booms. The B.E. Journal of Macroeconomics 12, Issue 1, pp. 1935-1690.

[10] Mortensen, D.L. and C.A. Pissarides, 1994. Job Creation and Job Destruction in the Theory of Unemployment. Review of Economic Studies 61, pp. 397-415.

[11] Peterson, M. and R. Rajan, 2002. Does Distance Still Matter? The Information Revolution in Small Business Lending. Journal of Finance 57, pp. 2533-2570.

[12] Quint, D. and P. Rabanal, 2011. Monetary and Macroprudential Policy in an Estimated DSGE Model of the Euro Area. Mimeo. 
[13] Ravenna, F. and C.E. Walsh, 2011. Welfare-Based Optimal Policy with Unemployment and Sticky Prices: A Linear-Quadratic Framework. Americal Economic Journal: Macroeconomics 3, pp. 130-162.

[14] Rogerson, R., R. Shimer, and R. Wright, 2005. Search-Theoretic Models of the Labor Market: Survey. Journal of Economic Literature XLIII, pp. 959-988.

[15] Suh, H., 2012. Macroprudential Policy: Its Effects and Relationship to Monetary Policy. Federal Reserve Bank of Philadelphia Working Paper No. 12-28.

[16] Teranishi, Y., 2008. Optiaml Monetary Policy under Staggered Loan Contracts. IMES Discussion Paper Series E-08, Bank of Japan.

[17] Wasmer, E. and P. Weil, 2000. The Macroeconomics of Labor and Credit Market Imperfections. American Economic Review 94(4), pp. 944-963.

[18] Woodford, M., 2003. Interest and Prices: Foundation of a Theory of Monetary Policy. Princeton University Press, Princeton, NJ. 
Table 1: Parameter Values

\begin{tabular}{clc}
\hline \hline Parameters & Explanation & Parameter values \\
\hline$\beta$ & Discount factor & 0.99 \\
$\sigma$ & Relative risk aversion & 2.0 \\
$\varepsilon$ & Elasticity of substitution between differentiated goods & 5.0 \\
$1-\omega$ & Probability of price adjustment & 0.2 \\
$\rho$ & Probability of losing credit line & 0.2 \\
$\kappa$ & Cost of posting vacancy & 0.5 \\
$\chi$ & Coefficient for the matching function & 0.5 \\
$\alpha$ & Substitution between $u_{t}$ and $v_{t}$ & 0.5 \\
$b=1-\alpha$ & Bargaining power of credit seeking firms & 0.5 \\
\hline
\end{tabular}




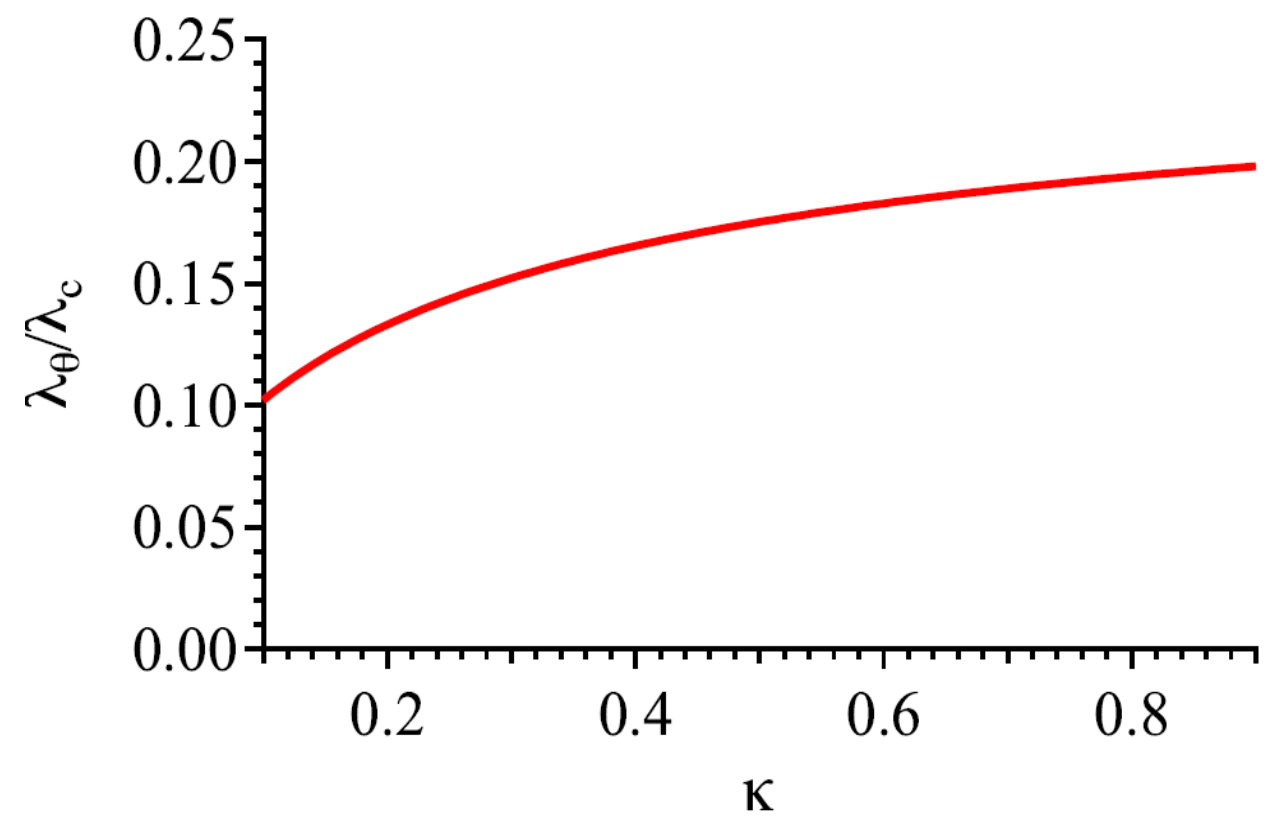

Figure 1: The dependence of the relative weight for credit to that for the consumption in the approximated welfare function on the cost of posting a credit vacancy. 


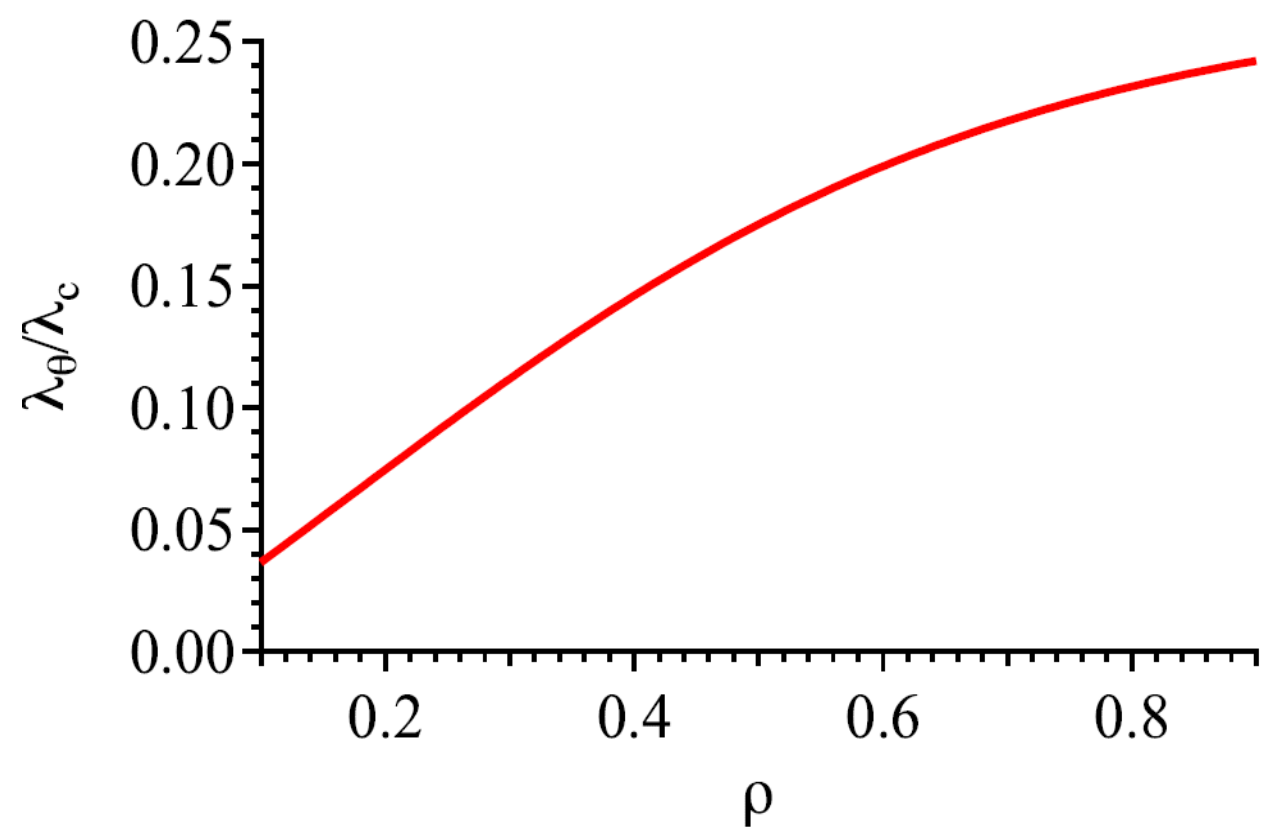

Figure 2: The dependence of the relative weight for credit to that for the consumption in the approximated welfare function on the probability of credit separation. 


\section{Appendix}

\section{A Policy Objective Function with Productivity Shock}

The models in the main text do not consider the effect of the productivity shock $Z_{t}$. This is because, even if $Z_{t}$ is taken into account as a shock, the mathematical forms of the model would remain the same by taking the difference from an efficient stochastic state equilibrium. In this subsection, we show that the productivity shock alters neither the policy objective function nor any of the linearized structural equations.

When we have a stochastic exogenous productivity $Z_{t}$, the second order expansion of the household's utility function around the efficient steady-state equilibrium becomes

$$
\begin{aligned}
& \sum_{i=0}^{\infty} \beta^{i} u\left(C_{t+i}\right)=-\frac{1}{2} \sum_{i=0}^{\infty} \beta^{i}\left(\lambda_{\pi} \pi_{t+i}^{2}+\lambda_{\theta} \widehat{\theta}_{t+i}^{2}+\lambda_{c} \widehat{c}_{t+i}^{2}\right) \\
&+u_{c} Z \bar{L} \sum_{i=0}^{\infty} \beta^{i}\left(\widehat{z}_{t+i}+\frac{1}{2} \widehat{z}_{t+i}^{2}\right)+u_{c} Z \bar{L} \sum_{i=0}^{\infty} \beta^{i} \widehat{z}_{t+i} \widehat{l}_{t+i}+t . i . p . .
\end{aligned}
$$

Here, although the term

$$
u_{c} Z \bar{L} \sum_{i=0}^{\infty} \beta^{i}\left(\widehat{z}_{t+i}+\frac{1}{2} \widehat{z}_{t+i}^{2}\right)
$$

is clearly t.i.p., the cross term between $\widehat{z}_{t+i}$ and $\widehat{l}_{t+i}$ seems relevant. In order to eliminate this term, we consider the log-linearized deviation from the dynamics of an efficient stochastic state. This efficient stochastic state is obtained by imposing the Hosios condition $b=1-\alpha$ and no price markup $\bar{\mu}=1$, but allowing the productivity shock $Z_{t}$ to move. We write the log-linearized value of a variable $X_{t}$ at the efficient stochastic state as $x_{t}^{e}$ and the deviation from the efficient stochastic state as $\widetilde{x}_{t} \equiv \widehat{x}_{t}-x_{t}^{e}$. At the efficient stochastic state, the consumption up to the first order is

$$
c_{t}^{e}=\frac{\bar{L}}{\bar{C}}\left(Z \widehat{z}_{t}-\beta \delta_{2} l_{t}^{e}+\delta_{2} l_{t-1}^{e}\right) .
$$

On the other hand, at the efficient stochastic equilibrium, the Euler equation (2) becomes

$$
c_{t}^{e}=\mathrm{E}_{t} c_{t+1}^{e}-\frac{1}{\sigma} r_{t}^{e},
$$

where $r_{t}^{e}$ is the real interest rate. By substituting the equation (43) into this equation, we obtain 


$$
\widehat{z}_{t}=\mathrm{E}_{t} \widehat{z}_{t+1}+\frac{\delta_{2}}{Z}\left(-\beta \mathrm{E}_{t} l_{t+1}^{e}+l_{t}^{e}+\beta l_{t}^{e}-l_{t-1}^{e}\right)-\frac{\bar{C}}{\sigma Z \bar{L}} r_{t}^{e} .
$$

The policy objective function can be expressed as

$$
\sum_{i=0}^{\infty} \beta^{i} u\left(C_{t+i}\right)=A_{t}+B_{t}+t . i . p .
$$

where

$$
A_{t}=u_{c} Z \bar{L} \sum_{i=0}^{\infty} \beta^{i} \widehat{z}_{t+i} \widehat{l}_{t+i}-\sigma u_{c} Z \bar{C} \delta_{2}\left(\frac{\bar{L}}{\bar{C}}\right)^{2} \sum_{i=0}^{\infty} \beta^{i}\left(\widehat{z}_{t+i} \widehat{l}_{t+i-1}-\beta \widehat{z}_{t+i} \widehat{l}_{t+i}\right)
$$

is the collection of the terms that include $\widehat{z}_{t}$, and

$$
B_{t}=-\frac{1}{2} \lambda_{\pi} \sum_{i=0}^{\infty} \beta^{i} \pi_{t+i}^{2}-u_{c} \kappa \bar{v} \frac{1-\alpha}{2} \sum_{i=0}^{\infty} \beta^{i} \widehat{\theta}_{t+i}^{2}-\frac{1}{2} \sigma u_{c} \bar{C}\left(\frac{\bar{L}}{\bar{C}} \delta_{2}\right)^{2} \sum_{i=0}^{\infty} \beta^{i}\left(-\beta \widehat{l}_{t+i}+\widehat{l}_{t+i-1}\right)^{2}
$$

represents the other terms. By using equation (44) only for the last term in $A_{t}$,

$$
\begin{aligned}
A_{t} & =u_{c} Z \bar{L} \sum_{i=0}^{\infty} \beta^{i} \widehat{z}_{t+i} \widehat{l}_{t+i}-\sigma u_{c} Z \bar{C} \delta_{2}\left(\frac{\bar{L}}{\bar{C}}\right)^{2} \sum_{i=0}^{\infty} \beta^{i}\left(\widehat{z}_{t+i} \widehat{l}_{t+i-1}-\beta \widehat{z}_{t+i+1} \widehat{l}_{t+i}\right) \\
& +\beta \sigma u_{c} Z \bar{C} \delta_{2}(\overline{\bar{L}})^{2} \sum_{i=0}^{\infty} \beta^{i}\left[\frac{\delta_{2}}{Z}\left(-\beta l_{t+i+1}^{e}+l_{t+i}^{e}+\beta l_{t+i}^{e}-l_{t+i-1}^{e}\right)-\frac{\bar{C}}{\sigma Z \bar{L}} r_{t+i}^{e}\right] \widehat{l}_{t+i} \\
& =u_{c} Z \bar{L} \sum_{i=0}^{\infty} \beta^{i} \widehat{z}_{t+i} \widehat{l}_{t+i}+t . i . p . \\
& +\beta \sigma u_{c} Z \bar{C} \delta_{2}\left(\frac{\bar{L}}{\bar{C}}\right)^{2} \sum_{i=0}^{\infty} \beta^{i}\left[\frac{\delta_{2}}{Z}\left(-\beta l_{t+i+1}^{e}+l_{t+i}^{e}+\beta l_{t+i}^{e}-l_{t+i-1}^{e}\right)-\frac{\bar{C}}{\sigma Z \bar{L}} r_{t+i}^{e}\right] \widehat{l}_{t+i} .
\end{aligned}
$$

On the other hand, equation (14) implies that, at the efficient stochastic equilibrium, we have

$$
Z \widehat{z}_{t}=(1-\alpha) \frac{\kappa \bar{v}}{\alpha \rho \bar{L}}\left(\theta_{t}^{e}-\beta \rho_{u} \mathrm{E}_{t} \theta_{t+1}^{e}\right)+\beta \delta_{2} r_{t}^{e}
$$

By substituting this, $A_{t}$ can be further simplified as 


$$
\begin{aligned}
A_{t} & =u_{c}(1-\alpha) \frac{\kappa \bar{v}}{\alpha \rho} \sum_{i=0}^{\infty} \beta^{i}\left(\theta_{t+i}^{e} \widehat{l}_{t+i}-\beta \rho_{u} \theta_{t+i+1}^{e} \widehat{l}_{t+i}\right) \\
& +\beta \sigma u_{c} \bar{C}\left(\delta_{2} \frac{\bar{L}}{\bar{C}}\right)^{2} \sum_{i=0}^{\infty} \beta^{i}\left(-\beta l_{t+i+1}^{e}+l_{t+i}^{e}+\beta l_{t+i}^{e}-l_{t+i-1}^{e}\right) \widehat{l}_{t+i}+t . i . p . \\
& =u_{c}(1-\alpha) \frac{\kappa \bar{v}}{\alpha \rho} \sum_{i=0}^{\infty} \beta^{i}\left(\rho_{u} \theta_{t+i}^{e} \widehat{l}_{t+i-1}-\beta \rho_{u} \theta_{t+i+1}^{e} \widehat{l}_{t+i}\right) \\
& +u_{c}(1-\alpha) \kappa \bar{v} \sum_{i=0}^{\infty} \beta^{i} \theta_{t+i}^{e} \widehat{\theta}_{t+i} \\
& +\beta \sigma u_{c} \bar{C}\left(\delta_{2} \frac{\bar{L}}{\bar{C}}\right)^{2} \sum_{i=0}^{\infty} \beta^{i}\left(-\beta l_{t+i+1}^{e}+l_{t+i}^{e}+\beta l_{t+i}^{e}-l_{t+i-1}^{e}\right) \widehat{l}_{t+i}+t . i . p .
\end{aligned}
$$

where $\widehat{\theta}_{t}=\frac{1}{\alpha \rho}\left(\widehat{l}_{t}-\rho_{u} \widehat{l}_{t-1}\right)$ is used. The two terms in the first summation on the right-hand side are again t.i.p., and the last summation can be rewritten as

$$
\begin{aligned}
& \sum_{i=0}^{\infty} \beta^{i}\left(-\beta l_{t+i+1}^{e}+l_{t+i}^{e}\right) \widehat{l}_{t+i}+\sum_{i=0}^{\infty} \beta^{i}\left(\beta l_{t+i}^{e}-l_{t+i-1}^{e}\right) \widehat{l}_{t+i} \\
& =\beta^{-1} \sum_{i=0}^{\infty} \beta^{i}\left(-\beta l_{t+i}^{e}+l_{t+i-1}^{e}\right) \widehat{l}_{t+i-1}-\beta^{-1}\left(-\beta l_{t}^{e}+l_{t-1}^{e}\right) \widehat{l}_{t-1}+\sum_{i=0}^{\infty} \beta^{i}\left(\beta l_{t+i}^{e}-l_{t+i-1}^{e}\right) \widehat{l}_{t+i} \\
& =\beta^{-1} \sum_{i=0}^{\infty} \beta^{i}\left(-\beta l_{t+i}^{e}+l_{t+i-1}^{e}\right)\left(-\beta \widehat{l}_{t+i}+\widehat{l}_{t+i-1}\right)+t . i . p . .
\end{aligned}
$$

We thus obtain

$$
\begin{aligned}
A_{t} & =\beta \sigma u_{c} \bar{C}\left(\frac{\bar{L}}{\bar{C}} \delta_{2}\right)^{2} \sum_{i=0}^{\infty} \beta^{i}\left(-\beta l_{t+i}^{e}+l_{t+i-1}^{e}\right)\left(-\beta \widehat{l}_{t+i}+\widehat{l}_{t+i-1}\right) \\
& +u_{c}(1-\rho) \kappa \bar{v} \sum_{i=0}^{\infty} \beta^{i} \theta_{t+i}^{e} \widehat{\theta}_{t+i}+t . i . p . .
\end{aligned}
$$

This expression for $A_{t}$ is substituted into the policy objective function of equation (45), yielding 


$$
\begin{aligned}
& \sum_{i=0}^{\infty} \beta^{i} u\left(C_{t+i}\right)=\beta \sigma u_{c} \bar{C}\left(\overline{\bar{L}} \delta_{2}\right)^{2} \sum_{i=0}^{\infty} \beta^{i}\left(-\beta l_{t+i}^{e}+l_{t+i-1}^{e}\right)\left(-\beta \widehat{l}_{t+i}+\widehat{l}_{t+i-1}\right) \\
&+u_{c}(1-\alpha) \kappa \bar{v} \sum_{i=0}^{\infty} \beta^{i} \theta_{t+i}^{e} \widehat{\theta}_{t+i} \\
&-\frac{1}{2} \lambda_{\pi} \sum_{i=0}^{\infty} \beta^{i} \pi_{t+i}^{2}-u_{c} \kappa \bar{v} \frac{1-\alpha}{2} \sum_{i=0}^{\infty} \beta^{i} \widehat{\theta}_{t+i}^{2} \\
&-\frac{1}{2} \sigma u_{c} \bar{C}\left(\frac{\bar{L}}{\bar{C}} \delta_{2}\right)^{2} \sum_{i=0}^{\infty} \beta^{i}\left(-\beta \widehat{l}_{t+i}+\widehat{l}_{t+i-1}\right)^{2}+t . i . p . \\
&=-\frac{1}{2} \lambda_{\pi} \sum_{i=0}^{\infty} \beta^{i} \pi_{t+i}^{2} \\
&-\frac{1}{2} \beta \sigma u_{c} \bar{C}\left(\frac{\bar{L}}{\bar{C}} \delta_{2}\right)^{2} \sum_{i=0}^{\infty} \beta^{i}\left[\left(-\beta \widehat{l}_{t+i}+\widehat{l}_{t+i-1}\right)-\left(-\beta l_{t+i}^{e}+l_{t+i-1}^{e}\right)\right]^{2} \\
&-u_{c} \kappa \bar{v} \frac{1-\alpha}{2} \sum_{i=0}^{\infty} \beta^{i}\left(\widehat{\theta}_{t+i}-\theta_{t+i}^{e}\right)^{2}+t . i . p . \\
&=-\frac{1}{2} \lambda_{\pi} \sum_{i=0}^{\infty} \beta^{i} \pi_{t+i}^{2}-\frac{1}{2} \beta \sigma u_{c} \bar{C}\left(\frac{\bar{L}}{\bar{C}} \delta_{2}\right)^{2} \sum_{i=0}^{\infty} \beta^{i}\left(-\beta \widetilde{l}_{t+i}+\widetilde{l}_{t+i-1}\right)^{2} \\
&-u_{c} \kappa \bar{v} \frac{1-\alpha}{2} \sum_{i=0}^{\infty} \beta^{i} \widetilde{\theta}_{t+i}^{2}+t . i . p . \\
&
\end{aligned}
$$

which can be simplified as:

$$
\sum_{i=0}^{\infty} \beta^{i} u\left(C_{t+i}\right)=-\sum_{i=0}^{\infty} \beta^{i} \frac{1}{2}\left(\lambda_{\pi} \pi_{t+i}^{2}+\lambda_{\theta} \widetilde{\theta}_{t+i}^{2}+\lambda_{c} \widetilde{c}_{t+i}^{2}\right) .
$$

We therefore confirm that the form of the utility-based policy objective function remains the same even when we introduce the productivity shock. In addition, we can easily see that all the relevant structural equations $(23,24,25,26$, and 27) can be written identically if we replace $\widehat{x}$ by $\widetilde{x}$ for all the variables of $X_{t}$.

\section{B Policy Objective Function with Time-Dependent Separa- tion Rate}

In this section, we show the derivation of equations (35) and (36).

The efficient steady-state condition is obtained by the following maximization problem: 


$$
\begin{aligned}
& \max _{C, L, u, \theta, \rho} \mathrm{E}_{t} \sum_{i=0}^{\infty} \beta^{i}\left\{\frac{C_{t+i}^{1-\sigma}}{1-\sigma}+\lambda_{t+i}\left[f\left(\rho_{t+i}\right) L_{t+i}-a L_{t+i}-\kappa \theta_{t+i} u_{t+i}-C_{t+i}\right]\right. \\
& \left.+\psi_{t+i}\left[\left(1-\rho_{t+i}\right) L_{t+i-1}+\chi \theta_{t+i}^{\alpha} u_{t+i}-L_{t+i}\right]+s_{t+i}\left[u_{t+i}-1+\left(1-\rho_{t+i}\right) L_{t+i-1}\right]\right\} .
\end{aligned}
$$

By taking the first-order conditions for the five variables and rearranging the equations, we obtain

$$
f\left(\rho_{t}\right)-a-\frac{\kappa \theta_{t}^{1-\alpha}}{\alpha \chi}=-\beta \mathrm{E}_{t} \frac{\lambda_{t+1}}{\lambda_{t}}\left(1-\rho_{t+1}\right)\left(\frac{\kappa \theta_{t+1}^{1-\alpha}}{\alpha \chi}+\frac{\alpha-1}{\alpha} \kappa \theta_{t+1}\right)
$$

and

$$
f^{\prime}\left(\rho_{t}\right) \frac{L_{t}}{L_{t-1}}=\frac{\kappa \theta_{t}^{1-\alpha}}{\alpha \chi}+\frac{\alpha-1}{\alpha} \kappa \theta_{t} .
$$

At the efficient steady-state equilibrium, the former condition becomes identical to equation (17), while the latter can be rearranged to condition (35).

We note that the latter equation, when linearized around the efficient steady-state equilibrium, is written as

$$
f_{2} \bar{\rho} \widehat{\rho}_{t}+f_{1}\left(\widehat{l}_{t}-\widehat{l}_{t-1}\right)=\frac{1-\alpha}{\alpha} \frac{\kappa \bar{\theta}^{1-\alpha}}{\chi}\left(1-\chi \bar{\theta}^{\alpha}\right)
$$

and could be obtained from the optimal policy in the main text, if there were no inflation. This point can be easily confirmed by substituting equation (30) into equation (40) to eliminate $\varphi_{3 t}$ and by remembering that $\varphi_{1 t}$ is zero without inflation from equation (29).

As for the second-order expansion of the utility, both the time-dependence of the separation rate $\rho_{t}$ and productivity $Z_{t}$ make calculation slightly complicated, although the basic procedure of derivation is straightforward. For example, productivity is factored in the expansion of consumption, and the equation corresponding to equation (18) becomes:

$$
\widehat{c}_{t}+\frac{1}{2} \widehat{c}_{t}^{2}=\frac{Z \bar{L}}{\bar{C}}\left(\widehat{z}_{t}+\frac{1}{2} \widehat{z}_{t}^{2}+\widehat{z}_{t} \widehat{l}_{t}-\widehat{q}_{t}\right)+\frac{(Z-a) \bar{L}}{\bar{C}}\left(\widehat{l}_{t}+\frac{1}{2} \widehat{l}_{t}^{2}\right)-\frac{\kappa \bar{v}}{\bar{C}}\left(\widehat{v}_{t}+\frac{1}{2} \widehat{v}_{t}^{2}\right)
$$

On the other hand, the expansion of credit vacancy (19) is modified by the time-dependence of the separation rate as: 


$$
\begin{aligned}
\widehat{v}_{t}+\frac{1}{2} \widehat{v}_{t}^{2} & =\left(\widehat{\theta}_{t}+\frac{1}{2} \widehat{\theta}_{t}^{2}\right)-\eta\left(\widehat{l}_{t-1}+\frac{1}{2} \widehat{l}_{t-1}^{2}\right)-\eta \widehat{\theta}_{t} \widehat{l}_{t-1} \\
& +\frac{\bar{\rho} \bar{L}}{\bar{u}}\left(\widehat{\rho}_{t}+\frac{1}{2} \widehat{\rho}_{t}^{2}+\widehat{\rho}_{t} \widehat{l}_{t-1}+\widehat{\rho}_{t} \widehat{\theta}_{t}\right) .
\end{aligned}
$$

After eliminating credit market tightness $\widehat{\theta}_{t}$ by using

$$
L_{t}=\left(1-\rho_{t}\right) L_{t-1}+\chi \theta_{t}^{\alpha} u_{t}
$$

we obtain the following expansion of the utility:

$$
\begin{aligned}
u\left(C_{t}\right) & =u(\bar{C})+u_{c} Z \bar{L}\left(\widehat{z}_{t}+\frac{1}{2} \widehat{z}_{t}^{2}+\widehat{z}_{t} \widehat{l}_{t}-\widehat{q}_{t}\right) \\
& -u_{c} \frac{\kappa \bar{v}}{\alpha}\left(1-(1-\alpha) \frac{\bar{\rho} \bar{L}}{\bar{u}}\right)\left(\widehat{\rho}_{t}+\frac{1}{2} \widehat{\rho}_{t}^{2}+\widehat{\rho}_{t} \widehat{l}_{t-1}\right) \\
& +u_{c} \bar{C}\left[\frac{\bar{L}}{\bar{C}}\left(\delta_{1} \widehat{l}_{t}+\delta_{2} \widehat{l}_{t-1}\right)+\frac{\bar{L}}{2 \bar{C}}\left(\delta_{1} \widehat{l}_{t}^{2}+\delta_{2} \widehat{l}_{t-1}^{2}\right)-\frac{\kappa \bar{v}}{\bar{C}} \frac{1-\alpha}{2(\alpha \rho)^{2}}\left(\widehat{l}_{t}-\rho_{u} \widehat{l}_{t-1}\right)^{2}\right] \\
& -\frac{1}{2} \sigma u_{c} \bar{C}\left(\frac{\bar{L}}{\bar{C}}\right)^{2}\left[Z \widehat{z}_{t}+\delta_{1} \widehat{l}_{t}+\delta_{2} \widehat{l}_{t-1}-\frac{\kappa \bar{v}}{\alpha \bar{L}}\left(1-(1-\alpha) \frac{\bar{\rho} \bar{L}}{\bar{u}}\right) \widehat{\rho}_{t}\right]^{2} .
\end{aligned}
$$

At this stage, by using equations (34) and (35), we observe that the first-order difference between $\widehat{z}_{t}$ and $\widehat{\rho}_{t}$ is cancelled, and we finally obtain equation (36). 